\title{
Serum Homocysteine Level Among Type-2 Diabetic Patients with and without Diabetic Retinopathy
}

\author{
Muktar Ali ${ }^{1}$, Zeba-un-Naher ${ }^{2 *}$, Md Aminul Haque Akhanda ${ }^{3}$, Sheeza Ali ${ }^{4}$ and Md Shamsul Haque ${ }^{5}$ \\ ${ }^{1}$ Consultant Ophthalmologist, Eye care Hospital Male, Maldives \\ ${ }^{2}$ Assistant Professor, School of Medicine, MNU, Male, Maldives \\ ${ }^{3}$ Associate Professor and Head, Department of Ophthalmology, Mymensingh Medical College, Mymensingh, Bangladesh \\ ${ }^{4}$ Dean, School of Medicine, MNU, Male', Maldives \\ ${ }^{5}$ Professor and Head, Department of Ophthalmology, Sir Salimulla Medical College, Dhaka, Bangladesh \\ *Corresponding Author: Zeba-un-Naher, Assistant Professor, School of Medicine, MNU, Male, Maldives.
}

Received: May 30, 2019; Published: July 04, 2019

DOI: 10.31080/ASMS.2019.03.0339

\begin{abstract}
Introduction: Considering the fact of sight threatening complication from diabetic retinopathy with increasing prevalence of diabetes throughout the world, researchers are in intense search to limit the development and progression of retinopathy from diabetes mellitus. Hyperhomocysteinemia is related to retinal vasculopathy seen in diabetic retinopathy. The aim of this study is to explore the association of serum homocysteine level among type 2 diabetic patients with and without diabetic retinopathy.

Methods: This is a cross sectional study performed at Department of Ophthalmology, Mymensingh Medical College Hospital, Mymensingh. Bangladesh. Here, 120 type 2 diabetic patients with and without diabetic retinopathy were taken by purposive and convenient sampling.

Then blood samples were collected from the study subjects to estimate serum homocysteine (Hcy), fasting blood sugar (FBS), total cholesterol (TC), triacylglycerol (TG), low density lipoprotein cholesterol (LDL-C) and high-density lipoprotein cholesterol (HDLC) and data were compiled for analysis.

Results: Homocysteine level was found to be significantly higher in cases $(19.17 \pm 6.13 \mu \mathrm{mol} / \mathrm{L})$ compared to controls $(11.75 \pm 4.43$ $\mu \mathrm{mol} / \mathrm{L})(\mathrm{p}<0.05)$.

Out of the total 120 study subjects, 53 subjects were found to have hyperhomocysteinemia (S. Hcy >15 $\mu$ mol/L). Among them 40 (75.47\%) subjects were with diabetic retinopathy of different grades. On the contrary among the 67 subjects with normal serum Hcy concentration $20(29.85 \%)$ subjects had diabetic retinopathy and these findings revealed hyperhomocysteinemia as a risk factor for diabetic retinopathy $(\mathrm{OR}>1)$.

Conclusion: Hyperhomocysteinaemia is associated with diabetic retinopathy and may play a role as a risk factor for the development of diabetic retinopathy.
\end{abstract}

Keywords: Hyperhomocysteinaemia; Serum Homocysteine; Diabetic

\section{Introduction}

Diabetes mellitus is a clinical syndrome characterized by hyperglycemia due to absolute or relative deficiency of insulin. This can arise in many different ways but is most commonly due to autoimmune type 1 diabetes or to adult onset type 2 diabetes. Diabetes occurs worldwide and the incidences of both type 1 and type 2 diabetes are rising. It is estimated that in the year 2000, 171 million people had diabetes, and this is expected to double by 2030 [1]. However, the prevalence of both types of diabetes varies considerably around the world and is related to differences in genetic and environmental factors. The prevalence of known diabetes in Britain is around 2-3\%, but is higher in the Middle and Far East, e.g. 12\% in the Indian subcontinent [2]. In a study conducted y Hussain., et 
al. [3] prevalence of diabetes (both types) in Bangladesh was found to be $8.1 \%$ in urban population and $2.3 \%$ in rural population. In a very recent study by Gupta P., et al. found that prevalence of hyperhomocysteinemia as well as the mean serum levels of homocysteine were higher in the cases with PDR (proliferative diabetic retinopathy), as compared to the controls with no retinopathy, although the difference was not statistically significant. Longer duration of diabetes, hypertension, anemia, and renal dysfunction, which are known risk factors for progression of DR (diabetic retinopathy), were found to be significantly associated with proliferative diabetic retinopathy.

Type 2 diabetes mellitus comprises approximately $90 \%$ of all cases of diabetes. Most patients acquire the disease after the age of 40 , but it may occur in younger people [4].

Diabetic retinopathy and diabetic macular edema are the leading causes of blindness in the working age group population of most developed and developing countries. The increasing number of individuals with diabetes worldwide suggests that diabetic macular edema will continue to be major contributors to vision loss and associated functional impairment [5].

Diabetic retinopathy is a well characterized, sight threatening, chronic, ocular disorder that eventually develops to some degree in nearly all patients with diabetes mellitus. The pathologic changes associated with diabetic retinopathy are similar in type 1 and 2 diabetes mellitus, although there is a higher risk of more frequent and severe ocular complications in type 1 diabetes. However, because more patients have type 2 than type 1 diabetes mellitus, patients with type 2 disease accounts for a higher proportion of those with visual loss [6].

Chronic hyperglycemia is considered to be the major risk factor for diabetic retinopathy, by inducing several biochemical pathways resulting in damage to the retinal vessel wall. Prolonged hyperglycemia provokes the activation of various intracellular metabolic pathways in endothelial cells and vascular smooth muscle cells. Auto-oxidation of glucose and its metabolic intermediates, increased mitochondrial production for superoxide anions, formation of advanced glycation end-products (AEGs) and increased activity of the sorbitol pathway result in an increase in the generation of free radicals, particularly reactive oxygen species (ROS) such as the superoxide anion, and there is also a decrease in the formation of antioxidants. These lead to increased oxidative stress. All these changes cause endothelial dysfunction in the retinal precapillary arterioles, capillaries, and venules and result in both microvascular leakage from breakdown of the inner blood-retinal barrier and microvascular occlusion leading to diabetic retinopathy [7].

Homocysteine is a highly reactive thiol-containing amino acid derived from the conversion of methionine to cysteine. As it is a thiol, it can undergo bio-oxidation and oxidation with other thiols. The resulting reactive oxygen species-hydrogen peroxide and superoxide anion radicals- generate oxidative stress [8].

Recent evidence also suggests that long-term exposure to hyperhomocysteinaemia damages the endothelium sufficiently to limit nitric oxide (NO) production and decreases the bioavailability of NO and also promotes lipid peroxidation, which may subsequently decrease the expression of endothelial nitric oxide synthase (eNOS) and directly degrades NO. Hyperhomocysteinaemia may lead to endothelial dysfunction via accumulation of asymmetric dimethylarginine (ADMA) which is an endogenous competitive inhibitor of eNOS [9-11].

Delen., et al. [12] observed higher Hcy levels in diabetic patients and particularly in those with micro and macrovascular complications. Wiltshire., et al. [13] have also reported similar finding.

Many cases of hyperhomocysteinaemia are found to be due to non-genetic factors. Two such factors are nutritional status and hormonal changes. An elevated plasma Hcy level may occur as a result of nutritional deficiencies of essential cofactors or enzyme substrates including cobalamin (vitamin B12), folate or pyridoxine (vitamin B6) [14]. Andersson A., et al. [15], Selhub J., et al. [16] and Ao M., et al. [17] in their study shows they have been suggested factors for increased Hcy levels, such as the deficiency of vitamin cofactors needed for Hcy metabolism, such as folic acid and vitamin B12, or the deficiency of any of the enzymes involved the remethylation [18] or transsulfuration [19] pathways of the Hcy metabolism.

Homocysteine evaluation may serve to identify diabetic patients predisposed to sight-threatening complications and more importantly the group of patients that may benefit from intensified screening and treatment strategies, including folic acid and vitamin B6 and B12 supplements, aimed ti limit or prevent the incidence and progression of diabetic retinopathy [14]. 


\section{Hypothesis}

Hyperhomocysteinaemia is associated with increased risk of diabetic retinopathy among patients of type 2 diabetes mellitus.

\section{Objectives}

General objectives

To explore the association of serum homocysteine level among type 2 diabetic patients with and without diabetic retinopathy.

\section{Specific objectives}

1. To measure and compare the serum homocysteine level in patients of type 2 diabetes mellitus without diabetic retinopathy, with non-proliferative diabetic retinopathy and with proliferative diabetic retinopathy.

2. To measure and compare lipid profile in patient of type 2 diabetes mellitus with and without diabetic retinopathy.

\section{Observation and Results}

Table 1 shows distribution and comparison of age between cases and controls. There was 60 cases and 60 controls. Age range in cases was $27-70$ years and Mean age was $50.25 \pm 9.77$ years. Age range of controls was $32-70$ years and mean age was 49.18 \pm 9.57 years. $t$-value between cases and controls was 0.604 . here, p-value was 0.05 .

\begin{tabular}{|c|c|c|c|c|}
\hline $\begin{array}{c}\text { Study } \\
\text { subjects }\end{array}$ & $\begin{array}{c}\text { Mean age } \\
\text { (yrs.) }\end{array}$ & $\begin{array}{c}\text { Range } \\
\text { (yrs.) }\end{array}$ & t-value & p-value \\
\hline $\begin{array}{c}\text { Case } \\
(\mathrm{n}=60)\end{array}$ & $50.25 \pm 9.77$ & $27-70$ & \multirow{2}{*}{0.604} & $>0.05^{\mathrm{NS}}$ \\
\cline { 1 - 3 } $\begin{array}{c}\text { Control } \\
(\mathrm{n}=60)\end{array}$ & $49.18 \pm 9.57$ & $32-70$ & & \\
\hline
\end{tabular}

Table 1: Distribution and comparison of age between cases and controls.

Unpaired t-test was done as the test of significance.

Table 2 shows distribution and comparison of sex between cases and controls. There was 60 cases and 60 controls. Among the cases number of males was 26 and female was 34 . Among the controls number of males was 27 and number of female was 33 . Chi-square (X2) value was 1.633. p-value was $>0.05$.

Table 3 shows the distribution of grouping of the cases.

Number of mild cases were $42(70.0 \%)$, moderate was 10 (16.7\%) and severe were 8 (13.3\%).

N.B: case- Non- Proliferative Diabetic Retinopathy.

\begin{tabular}{|l|c|c|c|c|}
\hline \multirow{2}{*}{ Study subjects } & \multicolumn{2}{|c|}{ Sex } & \multirow{2}{*}{$\mathbf{X}^{2}$ - value } & \multirow{2}{*}{ p- value } \\
\cline { 2 - 3 } & Male & Female & & \\
\hline Case $(\mathrm{n}=60)$ & 26 & 34 & 1.633 & $>0.05^{\mathrm{NS}}$ \\
\hline Control $(\mathrm{n}=60)$ & 27 & 33 & & \\
\hline
\end{tabular}

Table 2: Distribution and comparison of sex between cases and controls

Chi-square $\left(\mathbf{X}^{2}\right)$ test was done as the test of significance.

\begin{tabular}{|l|c|c|}
\hline \multicolumn{1}{|c|}{ Grouping } & Number & Percentage (\%) \\
\hline Mild NPDR & 42 & 70.0 \\
\hline Moderate NPDR & 10 & 16.7 \\
\hline Severe NPDR & 8 & 13.3 \\
\hline
\end{tabular}

Table 3: Distribution of grouping of the cases.

Table 4 shows the distribution of serum concentration of Hcy in cases and controls. Serum Hcy concentration of cases were in the range of $10-30 \mu \mathrm{mol} / \mathrm{l}$ and mean \pm SD concentration were 19.17 $\pm 6.13 \mu \mathrm{mol} / \mathrm{L}$. Serum Hcy concentration of controls were in the range of $6.00-25.90 \mu \mathrm{mol} / \mathrm{L}$ and mean \pm SD concentration were $11.75 \pm 4.43 \mu \mathrm{mol} / \mathrm{L}$.

\begin{tabular}{|l|c|c|}
\hline Study subjects & Mean \pm SD $(\boldsymbol{\mu m o l} / \mathbf{L})$ & Range $(\boldsymbol{\mu m o l} / \mathbf{L})$ \\
\hline Case $(n=60)$ & $19.17 \pm 6.13$ & $10.00-30.00$ \\
\hline Control $(n=60)$ & $11.75 \pm 4.43$ & $6.00-25.90$ \\
\hline
\end{tabular}

Table 4: Distribution of serum Homocysteine (Hcy) in the study subjects.

Table 5 shows median concentration of serum Hcy level of 60 cases were $18.41 \mu \mathrm{mol} / \mathrm{L}$ and of 60 control were $10.50 \mu \mathrm{mol} / \mathrm{L}$. Mann-Whitney U value was 566.50 and p-vale was $<0.05$.

\begin{tabular}{|l|c|c|c|}
\hline Study subjects & $\begin{array}{c}\text { Median } \\
(\boldsymbol{\mu m o l} / \mathrm{L})\end{array}$ & $\begin{array}{c}\text { Mann-Whitey } \\
\mathbf{U} \text { value }\end{array}$ & p-value \\
\cline { 1 - 2 } Case $(\mathrm{n}=60)$ & 18.41 & 566.50 & $<0.05^{\mathrm{s}}$ \\
\cline { 1 - 2 } Control $(\mathrm{n}=60)$ & 10.50 & & \\
\hline
\end{tabular}

Table 5: Distribution of comparison of Median concentration of serum Hcy level between cases and controls

Mann-Whitney U test was done as the test of significance. 
Table 6 shows mean fasting blood glucose level of cases were $13.25 \mathrm{mmol} / \mathrm{L}$ with a standard deviation (SD) of $\pm 4.93 \mathrm{mmol} / \mathrm{L}$ and of controls were $9.64 \mathrm{mmol} / \mathrm{L}$ with a $\mathrm{SD}$ of $\pm 2.67 \mathrm{mmol} / \mathrm{L}$. here $t$ value was 4.973 and $p$ value was $<0.001$.

- Mean TC level of cases were $215.00 \mathrm{mg} / \mathrm{dl}$ with a SD of \pm $40.98 \mathrm{mg} / \mathrm{dl}$ and controls were $196.00 \mathrm{mg} / \mathrm{dl}$ with a SD of $\pm 30.59 \mathrm{mg} / \mathrm{dl}$. t value was 2.772 and $\mathrm{p}$ value was $<0.001$.

- Mean TG level of cases were $253.00 \mathrm{mg} / \mathrm{dl}$ with a SD of \pm
$71.76 \mathrm{mg} / \mathrm{dl}$ and controls were $226.50 \mathrm{mg} / \mathrm{dl}$ with a SD of \pm $62.59 \mathrm{mg} / \mathrm{dl} / \mathrm{t} \mathrm{t}$ value was 2.162 and $\mathrm{p}$ value was $<0.05$.

- $\quad$ Mean LDL-C level of cases were $127.83 \mathrm{mg} / \mathrm{dl}$ with a SD of \pm $33.03 \mathrm{mg} / \mathrm{dl}$ and controls were $124.58 \mathrm{mg} / \mathrm{dl}$ with a SD of \pm $35.97 \mathrm{mg} / \mathrm{dl}$. $\mathrm{t}$ value was 0.515 and $\mathrm{p}$ value was $>0.05$.

- Mean HDL-C level of cases were $36.86 \mathrm{mg} / \mathrm{dl}$ with a SD of \pm $10.42 \mathrm{mg} / \mathrm{dl}$ and controls were $39.85 \mathrm{mg} / \mathrm{dl}$ with a $\mathrm{SD}$ of \pm $9.80 \mathrm{mg} / \mathrm{dl}$. $\mathrm{t}$ value was -1.614 and $\mathrm{p}$ value was $<0.05$.

\begin{tabular}{|c|c|c|c|c|}
\hline Parameter & Case Mean \pm SD $(n=60)$ & Control Mean \pm SD $(n=60)$ & t- value & p-value \\
\hline $\begin{array}{l}\text { Fasting blood glucose } \\
(\mathrm{mmol} / \mathrm{L})\end{array}$ & $\begin{array}{c}13.25 \pm 4.93 \\
(7.20-24.00)\end{array}$ & $\begin{array}{c}9.64 \pm 2.67 \\
(6.00-15.00)\end{array}$ & 4.973 & $<0.001^{\mathrm{s}}$ \\
\hline $\mathrm{TC}(\mathrm{mg} / \mathrm{dl})$ & $\begin{array}{c}215.00 \pm 40.98 \\
(160-280)\end{array}$ & $\begin{array}{c}196.00 \pm 30.59 \\
(140-250)\end{array}$ & 2.772 & $<0.001^{\mathrm{s}}$ \\
\hline $\mathrm{TG}(\mathrm{mg} / \mathrm{dl})$ & $\begin{array}{c}253.00 \pm 71.76 \\
(130-360)\end{array}$ & $226.50 \pm 62.59(110-310)$ & 2.162 & $<0.05^{\mathrm{s}}$ \\
\hline LDL-C (mg/dl) & $\begin{array}{c}127.83 \pm 33.03 \\
(80-195) \\
\end{array}$ & $\begin{array}{c}124.58 \pm 35.97 \\
(75-185) \\
\end{array}$ & 0.515 & $>0.05^{\mathrm{NS}}$ \\
\hline HDL-C (mg/dl) & $\begin{array}{c}36.86 \pm 1.42 \\
(20-55)\end{array}$ & $\begin{array}{c}39.85 \pm 9.80 \\
(25-60)\end{array}$ & -1.614 & $<0.05^{s}$ \\
\hline
\end{tabular}

Table 6: Comparison of blood glucose and lipid profile between cases and controls.

Unpaired ' $\mathrm{t}$ ' test was done as the test of significance.

Parenthesis show the ranges.

$\mathrm{TC}=$ Total cholesterol

$\mathrm{TG}=$ Triacylglycerol

LDL-C = Low density lipoprotein cholesterol

HDL-C = High density lipoprotein cholesterol

Table 7 shows out of 53 study subjects' serum Hcy level was $>15 \mu \mathrm{mol} / \mathrm{L}$ in 40 cases (75.47\%) and 130controls (24.57\%).

Out of 67 study subjects serum Hcy level was $<15 \mu \mathrm{mol} / \mathrm{l}$ in 20 cases $(29.85 \%)$ and 47 controls $(70.15 \%)$. Odd ratio was 1.31 .

Table 8 shows visual acuity of group-I was 0.34 and group-II it was 0.08. p value was $<0.001$.

\section{Discussion}

This is a hospital based cross sectional study. Here attempt was made to observe the association of serum homocysteine level among type 2 diabetic. Diabetic patients with and without diabetic

\begin{tabular}{|l|c|c|c|c|}
\hline Hcy $(\boldsymbol{\mu m o l} / \mathbf{L})$ & Cases & Controls & Total & OR \\
\hline$>15$ & $40(75.47 \%)$ & $13(24.57 \%)$ & 53 & \\
\cline { 1 - 4 }$<15$ & $20(29.85 \%)$ & $47(70.15 \%)$ & 67 & \multirow{2}{*}{1.31} \\
\cline { 1 - 4 } Total & 60 & 60 & 120 & \\
\hline
\end{tabular}

Table 7: Distribution of Risk assessment of diabetic retinopathy by odds ratio (OR) in hyperhomocysteinaemia in total study subjects $(n=120)$.

retinopathy. This study has compared serum Hcy level between 60 case (with diabetic retinopathy) and 60 controls (without diabetic retinopathy) of type 2 diabetes mellitus patients. 


\begin{tabular}{|l|c|c|}
\hline Study Group & Mean Visual Auity & p value \\
\hline Group-I $(n=60)$ & 0.34 & \\
\cline { 1 - 2 } Group-II $(n=60)$ & 0.08 & $<0.001^{\mathrm{s}}$ \\
\hline
\end{tabular}

Table 8: Distribution of visual acuity among the study subjects. Visual auity was expressed in log MAR unit.

Unpaired ' $\mathrm{t}$ ' test was done as the test of significance.

All the cases were non proliferative type of diabetic retinopathy of different grades. Among them 70.0\%, 16.7\% and 13.3\% cases of were mild, moderate and severe grade respectively (Table 3 ).

Fasting blood glucose and lipid profile were measured and compared between groups. To find the association of Hcy in the development od diabetic retinopathy odds ratio was calculated.

Age is the important factor for the development of retinopathy. Retinopathy in diabetic population increases with patients age. Retinopathy is rarely found in children younger than 10years of age. The risk of developing retinopathy increases after puberty. Retinopathy is commoner and most prevalent between the ages of 20 and 65 years. in the study of Brwon., et al. [20] mean age was 48 years ranging from 32 - 61 years. in the study of Hoogeven., et al. [21] mean age was $65.7 \pm 6.7$ years in the study of Larsson., et al. [22] age range was 15 - 50 years. age of patients in the current study was similar to the age of the patients of the above-mentioned studies. In this study mean age of the cases were $50.25 \pm 9.77$ years and of the controls were $49.18 \pm 9.57$ years (Table 1 ).

In this study, among the cases $43.34 \%$ were male and $56.67 \%$ were female. In controls group 45\% were male and 55\% were female and no significant difference was observed between sex distribution (Table 2). In the study of Gupta., et al. [23] female proportion was also higher.

Recently, elevated Hcy level has gained special consideration in relation to DR in several clinical studies, suggesting an association between elevated serum Hcy levels and the risk of DR Dos Santos Nunes M.K., et al. [24] and Dong N., et al. [25]. There is an association between hyperhomocysteinaemia and diabetes-induced microangiopathies (diabetic nephropathy, retinopathy and macular edema) Ukinc K., et al. [26] Studies suggested a strong relationship between elevated Hcy levels and DR. However, the exact role of hyperhomocysteinaemia in the development of DR is not clearly elucidated. There is clear evidence that Hcy induces the death of retinal ganglion cells in vitro Moore P., et al. [27] and in vivo Ganapathy P.S. [28].

Homocysteine is a recently recognized risk factor for the development of retinal vascular diseases. A number of studies have been conducted in the western world to explore the association between the development of retinopathy and hyperhomocycteinaemia. The study of Parvona., et al. [29], Young, Lu and Pan [30], Goldstein., et al. [31], Huang., et al. [32] and Brazionis., et al. [33] showed elevated serum homocysteine level in patients with retinopathy. In the study of Parvona., et al. [29] serum Hcy concentration in cases was $17.2 \pm 6.6 \mu \mathrm{mol} / \mathrm{l}$ and in controls was $12.3 \pm 4.1 \mu \mathrm{mol} / \mathrm{l}$. in the study of Goldstein., et al. [31] mean plasma Hcy level was $11.75 \pm 0.24$ $\mu \mathrm{mol} / \mathrm{l}$ in the control group and $15.86 \pm 1.34 \mu \mathrm{mol} / \mathrm{l}$ in DR group. In the study of Brazionis., et al. [33] serum Hcy concentration in cases was $11.5 \mu \mathrm{mol} / \mathrm{l}$ and in controls was $9.1 \mu \mathrm{mol} / \mathrm{l}$. In the current study serum Hcy concentration in cases was (19.17 $\pm 6.13 \mu \mathrm{mol} / \mathrm{l})$ which is significantly higher than that of controls $(11.75 \pm 4.43 \mu \mathrm{mol} / \mathrm{l})$ and this finding is similar to that of the studies mentioned above (Table 4).

But Agullo-Ortuno., et al. [34] and Tarkun., et al. [35] could not find any significant difference in Hcy level between subjects with and without retinopathy which might be due to their relatively small sample size.

The incidence and progression of retinopathy is associated with unadjusted serum cholesterol, this association was present even after adjust for age, gender and duration of diabetes, HbA1c and Basal Metabolic Index (BMI). Numerous studies have shown an association of serum cholesterol with severity of retinopathy [36]. Kareem., et al. [37] reported mean serum cholesterol level in retinopathy group was $262 \pm 11.30 \mathrm{mg} / \mathrm{dl}$ and in control group was $174 \pm 7.87 \mathrm{mg} / \mathrm{dl}$. Rema., et al. [36] showed that serum cholesterol level was higher in retinopathy group than that of without retinopathy group. In the current study serum total cholesterol was $215 \pm 40.98 \mathrm{mg} / \mathrm{dl}$ in cases and $196 \pm 30.59 \mathrm{mg} / \mathrm{dl}$ in controls. This result is very similar to the study of Chew., et al. [5] and Miccoli., et al. [38] (table 6).

Triglycerides is incorporated in to the cell membrane leading to changes in membrane fluidity and leakage of plasma constituents in to the retinal. This results in hemorrhage and edema in the retina (Freyberger., et al. 1994). The concentration of TG in the current study was $253 \pm 71.76 \mathrm{mg} / \mathrm{dl}$ in cases $226 \pm 62.59 \mathrm{mg} / \mathrm{dl}$ in controls (Table 6). Which is supported by the studies done by Kareem., 
et al. [37] and Reema., et al. [36]. Kareem., et al. [37] found significantly higher TG concentration in cases $(174 \pm 7.87 \mathrm{mg} / \mathrm{dl})$ than in controls group (151 $\pm 10.86 \mathrm{mg} / \mathrm{dl})$. Remma., et al. [36] found significantly higher TG concentration in cases than in controls.

In the current study LDL-C level was $127 \pm 33.03 \mathrm{mg} / \mathrm{dl}$ in cases and $124.58 \pm 35.97 \mathrm{mg} / \mathrm{dl}$ in controls (Table VI). Here, there is no significant difference in LDL-C concentration between cases and controls. This finding of no significant difference in LDL-C concentration between the group is similar with that of Dhir., et al. [39], Rema, Deepa and Mohan (2000), Tarkun., et al. [35], Parvona., et al. [40] and Nayak and Roberts [41]. Regarding the concentration of HDL-C this study found significantly lower level in cases $(36.86 \pm$ $10.42 \mathrm{mg} / \mathrm{dl})$ than controls $(39.85 \pm 9.80 \mathrm{mg} / \mathrm{dl})$. this finding differs with that of Nayak and Robert [41] and Rema., et al. [36]. This conflicting findings regarding different components of lipid profile may be due to different dietary habit, life style and ethnicity of our study subjects than that of the studies done abroad.

Chronic hyperglycemia is considered to be the major risk factor for diabetic retinopathy by inducing several biochemical pathways resulting in damage to the retinal vessel wall. In the current study fasting blood glucose level was also measured in cases and controls to find the hyperglycemic status and to compare between the study groups, where mean fasting blood glucose level were 13.25 $\pm 4.93 \mathrm{mmol} / \mathrm{l}$ in cases and $9.67 \pm 2.67 \mathrm{mmol} / \mathrm{l}$ in controls. This is significantly higher level in cases than controls. This finding is supported indirectly by the studies done by Parvona., et al. [40], Nayak and Roberts [41] who have assessed hyperglycemic status by measuring HbA1C. Kareem., et al. [37] found significant difference in hyperglycemic status by measuring both fasting blood glucose and HbA1C which strongly supports our findings and also establishes the fact that risk of diabetic retinopathy is directly related to the degree of hyperglycemia.

Considering serum Hcy concentration $>15 \mu \mathrm{mol} / \mathrm{l}$ as hyperhomocysteinaemia this study revealed hyperhomocysteinaemia as a risk factor for diabetic retinopathy in type 2 diabetes mellitus patient. The odds ration of retinopathy associated with hyperhomocysteinaemia was 1.31 (Table 7). OR=1 exposure is not a risk factor, OR>1 exposure is a risk factor (Hoque 2009). This finding is very similar with Hoogoven., et al. [21], Becker., et al. [42] and Brazionis., et al. [33]. In the study of Hoogeven., et al. [21] the OR was 1.13 and in the study of Brazionis., et al. [33] OR was 1.20. Tawfik A. [43] and Ibrahim A.S [44] showed a direct impact of excess Hcy on the blood-retinal barrier (BRB), induced retinal ischemia and neovascularization, increased vascular endothelial growth factor (VEGF) level in retina, activation of endoplasmic reticulum (ER) stress [45], activation of oxidative stress and induced epigenetic modifications (Wotherspoon F., et al. 2006).

Hard exudation along with macular edema is an important cause of visual deterioration in patients with diabetic retinopathy. Visual acuity was measured by Snellen chart and converted to log MAR values after Sihota and Tandon [46]. In the study of Brown., et al. [20] most of the patients had visual acuity worse than +1.0. in the study of Chew., et al. [5], 60\% patients had visual acuity worse than 0.3. in the current study visual acuity was expressed in log MAR unit. In Group-I patients mean visual acuity was 0.34 and in 0.34 and in Group-II patients was 0.08. In stud by Gupta p., et al. the prevalence of hyperhomocysteinemia was higher in PDR (59\%) compared to "No DR" (48.7\%); however, this difference was not statistically significant $(P=0.36)$. Similarly, to our study the mean serum homocysteine level of there in cases was higher than in controls, but this was not statistically significant $(17.98+6.26 \mu \mathrm{mol} / \mathrm{L}$ vs. $17.71+8.17 \mu \mathrm{mol} / \mathrm{L} ; \mathrm{P}=0.87$ ) for them. Longer duration of diabetes, hypertension, anemia, and renal dysfunction were found to be significantly associated with PDR. The prevalence of hyperhomocysteinemia as well as the mean serum levels of homocysteine were found to be higher in the cases with PDR, compared to the controls with No DR, although the difference was not statistically significant. Longer duration of diabetes, hypertension, anemia, and renal dysfunction were significantly associated with PDR [47-49].

\section{Conclusion}

From the above facts and findings, it may be concluded that hyperhomocysteinaemia is associated with diabetic retinopathy and may play a role as a risk factor for the development of diabetic retinopathy.

Hyperhomocyteinaemia might independently or synergistically with hyperglycemia, hypertriglyceridemia and low HDL-C participate in the pathophysiology of diabetic retinopathy which needs to be explored.

\section{Bibliography}

1. King H., et al. "Global burden of Diabetes, 1995-2025 Prevalence, numerical estimates, and projections”. Diabetes Care 21.9 (1998): 1414-1431. 
2. Frier BM and Fisher M. "Diabetes mellitus". in NA Boon, NR colledge, BR Walker and JAA Hunter (eds), Devidson's Principles and Practice of Medicine, 20th edn, Churchill Livingstone Elsevier, Philadelphia (2006): 808-848.

3. Hussain A., et al. "Type 2 diabetes in rural and urban population: Diverse prevalence and associated risk factors in Bangladesh". Diabetic Medicine 22.7 (2005): 931-936.

4. Sacks DB. Carbohydrates' in CA Burtis, ER Ashwood and DE Bruns (eds), TIETZ Textbook of Clinical Chemistry and Molecular Diagnostics, 4th edn, Saunders, Missoiuri 862.

5. Chew EY., et al. "Association of elevated serum lipid levels with retinal hard exudate in diabetic retinopathy. Eearly Treatment diabetic Retinopathy Study (ETDRS) Report 22". Archives of ophthalmology 114.9 (1996): 1079-1084.

6. Aiello LP. 200, 'Eye complications of Diabetes' in CR Khan (ed), Atlas of Diabetes, Science Press Limited, Cleveland Street, London (2000): 136.

7. Watkins PJ. "ABC of diabetes: retinopathy”. BML 326 (2003); 924-926.

8. Jacobsen DW. “Homocysteine-To Test and to Treat". (2006).

9. Welch GN and loscalzo J. "Homocysteine and Arterothrombosis". The New England Journal of Medicine 338.15 (1998): 1042-1050.

10. Endemann DH and Schiffrin EL. "Endothelial Dysfunction". Journal of the American Society of Nephrology 15.8 (2004):1983-1992.

11. Spoelstra-de Man., et al. "No effect of B vitamins on ADMA levels in patents at increased cardiovascular risk". Clinical Endocrinology 64. 5 (2006): 495-501.

12. Delen Y., et al. "Homocysteine Levels and catalase Activities in Type 2 Diabetic Subjects with Vascular Complications". Turkish journal of Endocrinology and Metabolism 5.1 (2001): 3941.

13. Wiltshire EJ., et al. "Endothelial Dysfunction Relates to Folate Status in Children and Adolescents With Type 1 Diabetes". Diabetes 51.7 (2002): 2282.
14. Fonseca V., et al. "Hyperhomocysteinemia and the Endocrine System: implications for Atherosclerosis and Thrombosis". Endocrine Reviews 20.5 (1999): 738-759.

15. Andersson A., et al. "Plasma homocysteine before and after methionine loading with regard to age, gender, and menopausal status". European Journal of Clinical Investigation 22.2 (1992): 79-87.

16. Selhub J., et al. "Vitamin status and intake as primary determinants of homocysteinemia in an elderly population". The Journal of the American Medical Association 270.22 (1993): 2693-2698.

17. Ao M., et al. "High prevalence of vitamin B-12 insufficiency in patients with Crohn's disease". Asia Pacific Journal of Clinical Nutrition 26.6 (2017): 1076-1081.

18. Ogier de Baulny H., et al. "Remethylation defects: Guidelines for clinical diagnosis and treatment". European Journal of Pediatrics 157.2 (1998): 77-83.

19. Mudd SH., et al. "The natural history of homocystinuria due to cystathionine beta-synthase deficiency". American Journal of Human Genetics 37.1 (1985): 1-31.

20. Brown GC., et al. "Lipemic diabetic retinopathy". Ophthalmology 91.12 (1984):1490-1495.

21. Hoogeveen EK., et al. "Hyperhomocysteinaemia is associated with the presence of retinopathy in type 2 diabetes mellitus: the Hoorn Study". Archives of internal medicine 160.19 (2000): 2984-2990.

22. Larsson., et al. "The association of hyperlipidemia with retinopathy in diabetic patients aged 15-50 years in the country of Umea". Acta ophthalmologica Scandinavica 77.5 (1999): 585-591.

23. Gupta A., et al. "Lipid-Lowering drug atorvastatin as an adjunct in the management of diabetic macular edema". American Journal of Ophthalmology 137.4 (2004): 675-782.

24. Dos Santos Nunes MK., et al. "Hypermethylation in the promoter of the MTHFR gene is associated with diabetic complications and biochemical indicators". Diabetology and Metabolic Syndrome 9 (2017): 84. 
25. Dong N., et al. "Plasma homocysteine levels are associated with macular thickness in type 2 diabetes without diabetic macular edema". International Ophthalmology 38.2 (2018): 737-746

26. Ukinc K., et al. "Methyltetrahydrofolate reductase C677T gene mutation and hyperhomocysteinemia as a novel risk factor for diabetic nephropathy". Endocrine 36.2 (2009): 255-261.

27. Moore P., et al. "Apoptotic cell death in the mouse retinal ganglion cell layer is induced in vivo by the excitatory amino acid homocysteine". Experimental Eye Research 73.1 (2001): 4557.

28. Ganapathy PS., et al. "Endogenous elevation of homocysteine induces retinal neuron death in the cystathionine-beta-synthase mutant mouse". Investigative Ophthalmology and Visual Science 50.9 (2009): 4460-4470.

29. Parvanova A., et al. "Hyperhomocysteinemia and Increased Risk of Retinopathy A cross-sectional, case-control study in patients with type 2 Diabetes". Diabetes Care 25.12 (2002): 2361.

30. Yang G Lu J and Pan C. "The impact of plasma homocysteine level on development of etinopathy in type 2 diabetes mellitus". Zhonghu Nei ke Za Zhi (in Chinese) 41.1 (2002): 34-38.

31. Golstein M., et al. "Hyperhomocysteinaemia in patients with diabetes mellitus with and without diabetic retinopathy". Eye 18.5 (2004): 460-465.

32. Huang EJ., et al. "Homocysteine and other biochemical parameters in Type 2 diabetes mellitus with different diabetic duration or diabetic retinopathy". Clinica Chimica Acta 366.1-2 (2006): 293-298.

33. Brazionis L., et al. "Homocysteine and Diabetic retinopathy". Diabetes Care (2007): dc07-0632.

34. Agulló-Ortuño MT., et al. "Plasmatic homocysteine concentration and its relationship with complications associated to diabetes mellitus". Clinica Chimica Acta 326.1 (2002): 105-112.

35. Tarkun 1., et al. "Homocysteine Concentrations in Type 2 Diabetes Mellitus Patients Without Cardiovascular Disease: relationship to Metabolic Parameters and Diabetic Complications". Turkish Journal of Endocrinology and Metabolism 1 (2003): 11-17.
36. Rema M., et al. "Association of serum lipids with diabetic retinopathy in urban South Indian-the Chennai Urban Rural Epidemiology Study (CURES) Eye Study -2". Diabetic Medicine 23.9 (2006): 1029-1036.

37. Kareem I., et al. "Study of Megnesium, Glycosylated Hemoglobin and Lipid Profile in Diabetic Retinopathy". Indian Journal of Clinical Biochemistry 19.2 (2004): 124-127.

38. Miccoli R., et al. "Circulating lipid levels and severity of diabetic retinopathy in type 1 diabetes mellitus". Ophthalmic Research 19.1 (1987): 52-56.

39. Dhir SP., et al. "Serum lipoprotein cholesterol profile in diabetic retinopathy". Indian Journal of Ophthalmology 32.2 (1948): 89-91.

40. Parvanova A., et al. "Insulin resistance and Proliferative retinopathy: a cross-sectional, case-control study in 115 Patients with type 2 diabetes". The Journal of Clinical Endocrinology and Metabolism 89.9 (2004): 4371-4376.

41. Nayak BS and Roberts L. "Relationship between inflammatory markers, metabolic and anthropometric variables in the Caribbean type 2 diabetic patients with and without microvascular complications". Journal of Inflammation (Lond) 3 (2006): 17.

42. Becker A., et al. "Epidemiology of Homocysteine as a Risk Factor in Diabetes". Metabollic Syndrome and Related Disorders 1.2 (2003): 105-120.

43. Tawfik A., et al. "Alterations of retinal vasculature in cystathionine-Beta-synthase mutant mice, a model of hyperhomocysteinemia". Investigative Ophthalmology and Visual Science 54.2 (2013): 939-949.

44. Ibrahim AS., et al. "Hyperhomocysteinemia disrupts retinal pigment epithelial structure and function with features of age-related macular degeneration". Oncotarget 7.8 (2016): 8532-8545.

45. Tawfik A and Smith SB. "Increased ER stress as a mechanism of retinal neurovasculopathy in mice with severe hyperhomocysteinemia". Austin Journal of Clinical Ophthalmology 1.5 (2014): 1023-1029.

46. Sihota R and Tandon R. 'Parson's Diseases of the Eye". 19th edn, Butterworth Heinmann, (2003): 93-95. 
47. Abbot Diagnostics. "Homocysteine estimation: Fluorescence polarization immunoassay (FPIA) AxSYM". Abbot Laboratories, Abbot Park, Illinois, U.S.A. (2006).

48. Gupta P., et al. "Role of hyperhomocysteinemia in proliferative diabetic retinopathy: A case-control study". Indian journal of ophthalmology 66.10 (2018): 1435-1440.

49. Mohamed R., et al. "Hyperhomocysteinemia alters retinal endothelial cells barrier function and angiogenic potential via activation of oxidative stress". Scientific Reports 7 (2017): 11952.

Volume 3 Issue 8 August 2019

(C) All rights are reserved by Zeba-un-Naher., et al. 